\title{
The Potential Role of Iodine-123 Metaiodobenzylguanidine Imaging for Identifying Sustained Ventricular Tachycardia in Patients with Cardiomyopathy
}

\author{
Thomas Klein • Vasken Dilsizian • Qi Cao • \\ Wengen Chen • Timm-Michael Dickfeld
}

Published online: 29 March 2013

(C) The Author(s) 2013. This article is published with open access at Springerlink.com

\begin{abstract}
Implantable cardioverter-defibrillators (ICDs) significantly reduce mortality in patients with depressed left ventricular ejection fraction (LVEF) and heart failure (HF). However, shortcomings of LVEF to accurately identify those at greatest risk of ventricular tachyarrhythmias have led to the pursuit of alternative means to refine qualification criteria for ICD implantation. It is well established that imaging the cardiac nervous system with ${ }^{123}$ I metaiodobenzylguanidine $\left({ }^{123} \mathrm{I}-m \mathrm{IBG}\right)$ provides incremental prognostic value in patients with HF beyond LVEF. Whether ${ }^{123} \mathrm{I}-m \mathrm{IBG}$ will also play an important role for identifying and/or predicting sustained ventricular tachyarrhythmias in patients with cardiomyopathy and determining those who may benefit from ICD implantation is currently under investigation. Novel imaging approaches that pinpoint the site of ventricular arrhythmias and guide ventricular tachycardia ablation are presented.
\end{abstract}

Keywords Cardiac $m \mathrm{IBG} \cdot$ Cardiomyopathy $\cdot$ Ventricular tachycardia $\cdot$ Cardiac arrhythmia $\cdot$ Heart failure $\cdot$ Ablation therapy $\cdot$ Cardiomyopathy

This article is part of the Topical Collection on Nuclear Cardiology

T. Klein · T.-M. Dickfeld $(\bowtie)$

Maryland Arrhythmia and Cardiology Imaging Group (MACIG),

Department of Medicine, Division of Cardiology,

University of Maryland Medical Center,

22 South Greene St, Baltimore, MD 21201, USA

e-mail: tdickfel@medicine.umaryland.edu

V. Dilsizian $\cdot$ Q. Cao $\cdot$ W. Chen

Department of Diagnostic Radiology and Nuclear Medicine,

University of Maryland Medical Center,

22 South Greene Street, Baltimore, MD 21201, USA

\section{Introduction}

Sudden cardiac death is a significant public health issue, affecting 150,000-450,000 patients in the United States each year $[1,2]$. Clinical trial data has shown that implantable cardioverter-defibrillators (ICDs) significantly reduce mortality in patients with depressed left ventricular ejection fraction (LVEF) and heart failure (HF), whereas antiarrhythmic medication has not been shown to have the same benefits compared to placebo [3, 4]. Identifying patients at risk for developing ventricular tachyarrhythmias who will benefit from ICD placement for primary prevention has been the objective of a multitude of large clinical trials over the past two decades. The focus has been on patients with structural heart disease, and the most valuable discriminator currently in use is LVEF. However, the majority of patients who suffer SCD do not have characteristics that would qualify them for an ICD for primary prevention $[5,6]$. Furthermore, in a large randomized primary prevention ICD implantation trial, over two thirds of patients who received ICDs with depressed LVEF never received ICD therapy during a follow-up period of almost 2 years [7]. These shortcomings of LVEF to accurately identify those at greatest risk of ventricular arrhythmias (VTA) have led to the pursuit of alternative means to refine implantation qualification criteria for ICDs.

Signal-averaged electrocardiogram (ECG), microvolt Twave alternans, electrophysiologic testing, serum markers (including brain natriuretic peptide), and autonomic function evaluation (including heart rate variability (HRV), baroreflex sensitivity, heart rate turbulence, and deceleration capacity of heart rate) have all been studied, and have produced variable results [8]. More recently, imaging the cardiac nervous system has proven to have incremental prognostic value in patients with HF beyond LVEF and Btype natriuretic peptide (BNP).This article will summarize 
the data on imaging cardiac innervations with ${ }^{123} \mathrm{I}$ metaiodobenzylguanidine ( $\left.{ }^{123} \mathrm{I}-m \mathrm{IBG}\right)$ SPECT and its potential role in predicting the risk of VTA and describe novel imaging approaches to identify the site of VTA to guide ventricular tachycardia (VT) ablation.

\section{Imaging the Cardiac Sympathetic Nervous System}

${ }^{123} \mathrm{I}-\mathrm{mIBG}$ has been the most common radiotracer studied for imaging cardiac innervation. It was first introduced in 1979 for imaging the adrenal medulla, and for the heart shortly thereafter [9]. ${ }^{123}$ I- $m$ IBG is chemically modified from guanethidine, which is an analogue of the endogenous neurotransmitter norepinephrine, and uses the same uptake and storage mechanisms as norepinephrine. Two mechanisms of ${ }^{123} \mathrm{I}-m \mathrm{IBG}$ uptake from the synaptic cleft have been identified, one being neuronal and the other being non-neuronal, of which the former predominates in the human heart. This is evidenced by the fact that uptake is absent in enervated transplanted hearts [10]. Unlike norepinephrine, ${ }^{123} \mathrm{I}-m \mathrm{IBG}$ is not metabolized by monoamine oxidase or catechol-O-methyltransferase, and does not interact with postsynaptic receptors. Thus, cardiac ${ }^{123} \mathrm{I}-m \mathrm{IBG}$ reflects uptake in only presynaptic sympathetic fibers in the myocardium [11].

${ }^{123} \mathrm{I}-m \mathrm{IBG}$ cardiac images are usually acquired in the anterior planar view 5-40 minutes (early) and again 34 hours (delayed) after the injection of the radiotracer. From these planar images, the heart-to-mediastinal ratio $(\mathrm{H} / \mathrm{M})$ is calculated by dividing the mean counts per pixel from a cardiac region of interest by the mean counts per pixel from an area in the upper mediastinum. Delayed H/M ratio derived from the anterior planar view has been widely used to predict patient outcome and monitor response to medical treatment. In addition, ${ }^{123} \mathrm{I}-m \mathrm{IBG}$ washout rate (WR) is calculated by comparing early and delayed ${ }^{123} \mathrm{I}-$ $m$ IBG activities in the heart, reflecting the retention or turnover of ${ }^{123} \mathrm{I}-m \mathrm{IBG}$ in neurons. After each planar acquisition, a SPECT acquisition is performed, and images are analyzed in conventional orthogonal planes (short axis, vertical long axis, and horizontal long axis).

The reproducibility and inter-observer variability of ${ }^{123} \mathrm{I}$ $m$ IBG in HF patients at single centers has been found to be acceptable and highly reproducible [12]. However, interinstitutional variations exist which have been attributed to the use of different collimators, image acquisition parameters, injected doses, region of interest settings, ${ }^{123} \mathrm{I}-\mathrm{mIBG}$ labeling methods, disease status, and ${ }^{123} \mathrm{I}-m \mathrm{IBG}$ isotopes[13]. Also, some patterns across patient populations have been noted. For example, in healthy subjects, inferior wall uptake of ${ }^{123} \mathrm{I}$ $m I B G$ may decrease with age, especially in men [14]. Given the inter-institutional variations, a standardized protocol was recently proposed by the Cardiovascular Committee and the European Council of Nuclear Cardiology [11].

\section{The Clinical Utility of ${ }^{123}$ I- $m$ IBG in HF}

The autonomic nervous system is known to play a key role in the pathophysiology of HF. Neurohormonal feedback provides a means for compensation in the early stages of HF; however, as the disease progresses, chronic sympathetic output leads to detrimental effects, including interstitial fibrosis and left ventricular remodeling. Chronically elevated norepinephrine levels have been linked to an increased risk of mortality in HF [15]. Additionally, pharmacologic blockade of the sympathetic input to the heart decreases mortality in these patients $[16,17]$.

Multiple clinical trials have evaluated ${ }^{123} \mathrm{I}-m \mathrm{IBGin}$ HF patients. Patients with HF exhibit decreased cardiac uptake of ${ }^{123} \mathrm{I}-m \mathrm{IBG}$ (decreased H/M), and earlier release of ${ }^{123} \mathrm{I}$ $m \mathrm{IBG}$ from early to delayed imaging due to compromised neuronal integrity (increased WR). An inverse relationship has been shown between severity of HF classification and $\mathrm{H} / \mathrm{M}^{123} \mathrm{I}-m \mathrm{IBG}$ ratio. Retrospective and single center studies over the past two decades have demonstrated that ${ }^{123} \mathrm{I}$ $m$ IBGuptake predicts the risk of cardiac death cardiomyopathy (Table 1) [18-25]. Preliminary data also suggest salutary effects of medical therapy on cardiac ${ }^{123} \mathrm{I}-m \mathrm{IBG}$ uptake and its relation to clinical outcomes $[19,26]$. Several small series have demonstrated improvement in sympathetic innervation, as assessed with ${ }^{123} \mathrm{I}-m \mathrm{IBG}$ scintigraphy, resulting from cardiac resynchronization therapy and left ventricular assist device therapy, which paralleled multiple clinical parameters [27-29]. Conversely, non-responders to CRT did not demonstrate the same improvements in sympathetic innervation [30, 31].

A meta-analysis of 18 small trials including 1755 patients was published in 2008, and demonstrated that decreased $\mathrm{H} / \mathrm{M}$ and elevated WR portends a worse prognosis, with increased risk of cardiac death and cardiac events [32]. Based on the aforementioned data and similar results in previously published trials, ${ }^{123} \mathrm{I}-m \mathrm{IBG}$ has gained clinical use in Europe and Japan in HF patients and for cardiac transplantation candidacy since the 1990s. In the U.S., however, ${ }^{123} \mathrm{I}-m \mathrm{IBG}$ has not yet received Food and Drug Administration (FDA) approval for cardiac application [33].

AdreView Myocardial Imaging for Risk Evaluation in Heart Failure (ADMIRE-HF) prospective, multinational, multicenter, open-label study which enrolled 961 patients with LVEF $\leq 35 \%$ and New York Heart Association (NYHA) functional class II-III was recently completed [34••]. Patients underwent both ${ }^{123} \mathrm{I}-m \mathrm{IBG}$ and myocardial perfusion imaging and were followed for two years. The subgroup of patients with ${ }^{123} \mathrm{I}-m \mathrm{IBGH} / \mathrm{M}<1.6$ had a 2 -year 
Table 1 Relevant Studies studies on $m$ IBG Scintigraphy scintigraphy for Prognosis prognosis in HF

\begin{tabular}{|c|c|c|c|c|c|c|c|}
\hline Year & Author & $\mathrm{n}=$ & $\begin{array}{l}\text { Etiology } \\
(\% \text { ICM) }\end{array}$ & $\begin{array}{l}\text { Mean } \\
\text { baseline } \\
\text { LVEF }(\%)\end{array}$ & NYHA Class & $\begin{array}{l}\text { Mean } \\
\text { Follow-up } \\
\text { (months) }\end{array}$ & Result \\
\hline 1992 & Merlet, et al. [18] & 90 & 27 & 22 & II-IV & 11 & $\begin{array}{l}\mathrm{H} / \mathrm{M} \text { was more valuable in predicting survival } \\
\text { than } \mathrm{x}-\text {-ray cardiothoracic ratio, echocardio- } \\
\text { graphic end-diastolic diameter and } \\
\text { radionuclide LVEF }\end{array}$ \\
\hline 1998 & Nakata, et al. [35] & 414 & 32 & 49 & 1.6 (mean) & 22 & $\begin{array}{l}\text { Late } \mathrm{H} / \mathrm{M} \text {, early } \mathrm{H} / \mathrm{M} \text {, use of nitrates, and } \mathrm{LVEF} \\
\text { were all predictive of cardiac death, but late } \\
\mathrm{H} / \mathrm{M} \text { was the most powerful predictor }\end{array}$ \\
\hline 1999 & $\begin{array}{c}\text { Cohen-Solal, } \\
\text { et al. [20] }\end{array}$ & 93 & 26 & 25 & 2.6 (mean) & 10 & $\begin{array}{l}\text { In patients with chronic } \mathrm{HF} \text {, late } \mathrm{H} / \mathrm{M} \text { and peak } \\
\text { oxygen consumption were predictive of death } \\
\text { or heart transplantation, but only peak VO2 } \\
\text { was significant by multivariate analysis }\end{array}$ \\
\hline 1999 & Merlet, et al. [24] & 112 & 0 & 21 & II-IV & 27 & $\begin{array}{l}\text { Of several variables tested, only late } \mathrm{H} / \mathrm{M} \text { and } \\
\text { LVEF were predictive of mortality in idiopathic } \\
\text { nonischemic cardiomyopathy }\end{array}$ \\
\hline 2001 & $\begin{array}{l}\text { Imamura, } \\
\text { et al. [23] }\end{array}$ & 171 & 56 & 27 & 1.9 (mean) & 27 & $\begin{array}{l}\text { Elevated WR was an independent predictor of } \\
\text { cardiac death; elevated WR and BNP predicted } \\
\text { progressive HF }\end{array}$ \\
\hline 2001 & Ogita, et al. [25] & 79 & 57 & 29 & 1.8 (mean) & 31 & $\begin{array}{l}\text { WR } \geq 27 \% \text { predicted SCD, HF death, and } \\
\text { worsening HF }\end{array}$ \\
\hline 2002 & Gerson, et al. [26] & 22 & 0 & 25 & II-IV & 7.2 & $\begin{array}{l}\text { Patients with abnormal baseline }{ }^{123} \text { I- } m \text { IBG uptake } \\
\text { demonstrated improvement in }{ }^{123} \text { I- } m \text { IBG uptake } \\
\text { with carvedilol treatment, which correlated with } \\
\text { improvement in LVEF. }\end{array}$ \\
\hline 2003 & Kasama, et al. [36] & 30 & 0 & 33 & 2.8 (mean) & 6 & $\begin{array}{l}\text { Spironolactone decreased total defect score, and } \\
\text { WR and increased H/M in HF patients to placebo. } \\
\text { These changes correlated with improvement in } \\
\text { LVEF, LV end-diastolic volume, and NYHA class. }\end{array}$ \\
\hline 2003 & Yamada, et al. [21] & 65 & 63 & 28 & 2.1 (mean) & 34 & $\begin{array}{l}\text { In multivariate analysis, only WR (not } \mathrm{H} / \mathrm{M} \text { or HRV) } \\
\text { was predictive of cardiac events }\end{array}$ \\
\hline 2005 & Nakata, et al. [19] & 88 & 27 & 27 & 2.6 (mean) & 43 & $\begin{array}{l}\text { Less severe }{ }^{123} \mathrm{I} \text { - } m \mathrm{IBG} \text { defect correlated with } \\
\text { improved treatment effect from beta-blockers } \\
\text { and/or ACE inhibitors (Mortality reduction from } \\
36 \% \text { to } 12 \% \text { in those with } \mathrm{H} / \mathrm{M} \geq 1.53 \text {, from } \\
53 \% \text { to } 37 \% \text { in those with } \mathrm{H} / \mathrm{M}<1.53 \text { ) }\end{array}$ \\
\hline 2008 & Agostini, et al. [22] & 290 & 42 & 32 & 2.5 (mean) & 24 & $\begin{array}{l}\text { In this retrospective analysis, decreased H/M LVEF } \\
\text { were both predictive of major cardiac events }\end{array}$ \\
\hline 2008 & Kasama, et al. & 208 & 42 & 32 & 2.6 (mean) & 53 & $\begin{array}{l}\text { Patients underwent serial }{ }^{123} \text { I- } m \text { IBG imaging, and } \Delta \\
\text { WR was shown to be an incremental predictor of } \\
\text { cardiac death and sudden death }\end{array}$ \\
\hline 2010 & $\begin{array}{l}\text { Jacobson, } \\
\text { et al. }[34 \bullet \bullet]\end{array}$ & 961 & 66 & 27 & 2.16 (mean) & 17 & $\begin{array}{l}\text { Late } \mathrm{H} / \mathrm{M} \text {, in addition to } \mathrm{LVEF}, \mathrm{BNP} \text {, and NYHA } \\
\text { class was an independent predictor of HF } \\
\text { progression, arrhythmic events, and cardiac death. }\end{array}$ \\
\hline
\end{tabular}

cardiac event rate (progression of NYHA class, potentially life threatening arrhythmias, or cardiac death) of $37 \%$, while those with $\mathrm{H} / \mathrm{M} \geq 1.6$ had a 2 -year event rate of $15 \%$. Each of the three components of the primary outcome were also significantly reduced in patients with $H / M \geq 1.6$ (composite primary outcome: $\mathrm{HR}=0.4, \mathrm{p}<0.001$; $\mathrm{HF}$ progression: $\mathrm{HR}=0.49, \mathrm{p}=0.002$; life-threatening arrhythmia: $\mathrm{HR}=0.37, \mathrm{p}=0.02$; cardiac death: $\mathrm{HR}=0.14, \mathrm{p}=0.006)$. LVEF, BNP, NYHA class, and H/M were significantly predictive of event occurrence in multivariate analysis. Although
WR was predictive in univariate analysis, it did not remain so in multivariate analysis.

\section{${ }^{123}$ I-mIBG for Assessment of Ventricular Arrhythmia Risk}

Activation of sympathetic nervous system is an important factor in the pathophysiology of ventricular tachyarrhythmias. All three known mechanisms of ventricular tachyarrhythmias, 
including enhanced automaticity, triggered automaticity, and reentrance, can be potentiated by the sympathetic nervous system. Sympathetic neuronal innervation has been shown to be denser in those with ventricular arrhythmias than in those without [37]. It is theorized that denervated but viable myocardium may demonstrate an exaggerated response to circulating catecholamines [38].

It was observed over two decades ago that abnormal ${ }^{123} \mathrm{I}-$ $m$ IBGuptake was present after myocardial infarction (MI) and correlated with ventricular ectopy [39] and with inducible ventricular tachyarrhythmias during invasive electrophysiologic testing [40], as well as in patients without coronary artery disease but with spontaneous ventricular tachyarrhythmias [41]. These small series sparked a long pursuit to uncover the predictive value of ${ }^{123} \mathrm{I}-m$ IBGfor ventricular tachyarrhythmias, to refine the utilization of ICDs, and to determine a possible clinical role for cardiac ${ }^{123}$ I- $m$ IBGtesting. Multiple studies have evaluated the value of ${ }^{123} \mathrm{I}-m \mathrm{IBGimaging}$ in diverse groups of patients to predict the risk of ventricular tachyarrhythmias, sudden cardiac death, and ICD discharges (Table 2) [42-51].

HF Patients. Prospective observational studies have shown that ${ }^{123}$ I- $m$ IBG may predict the risk of ICD discharges in patients with mild-to-moderate HF. In 97 patients with LVEF $<40 \%$ and an average NYHA functional class II who underwent cardiac ${ }^{123} \mathrm{I}-m \mathrm{IBG}$ imaging, both WR and early and late $\mathrm{H} / \mathrm{M}$ were predictive of sudden cardiac death [52]. Over a mean follow-up of 65 months, the prevalence of sudden cardiac death was significantly higher in patients with ${ }^{123} \mathrm{I}-m \mathrm{IBG} \mathrm{WR} \geq 27 \%$ compared to those with $\mathrm{WR}<$ $27 \% ; 25 \%$ and $4 \%$, respectively. In another series of patients with NYHA class I-II HF and recent ICD implantation, ${ }^{123} \mathrm{I}-m \mathrm{IBG} \mathrm{WR}$, in addition to baroreflex sensitivity and heart rate variability, was found to correlate directly with the incidence of ICD firings [53].

The largest prospective, multicenter study to date designed to examine the predictive value of ${ }^{123} \mathrm{I}-m \mathrm{IBG}$ scintigraphy for predicting ICD implantation and discharge in HF patients was published in 2010. Among 116 patients (mean $\mathrm{LVEF}=28 \%$, $96 \%$ ischemic etiology, mean NYHA class $=2.9$ ) who underwent ${ }^{123} \mathrm{I}-m \mathrm{IBG}$ cardiac imaging prior to ICD implantation, $52 \%$ of patients with large ${ }^{123} \mathrm{I}-m \mathrm{IBG}$ defects (summed score $>26$ ) received appropriate ICD therapy (primary endpoint) during a mean follow up period of 23 months versus only $5 \%$ of patients with a smaller ${ }^{123} \mathrm{I}-m \mathrm{IBG} \operatorname{defect}(\mathrm{p}<0.01)$. Moreover, $57 \%$ of those with a large ${ }^{123}$ I- $m$ IBG defect experienced the secondary endpoint of appropriate ICD discharge or cardiac death versus only $10 \%$ of those with smaller defects $(\mathrm{p}<0.01)[54 \cdot \bullet]$.

Non-HF Patients. Populations known to be at risk for ventricular tachyarrhythmias but without a history of HF have also been evaluated for cardiac ${ }^{123} \mathrm{I}-m \mathrm{IBG}$ abnormalities. In patients with Brugada syndrome, $47 \%$ were found to have regional ${ }^{123} \mathrm{I}-m \mathrm{IBG}$ defects, most commonly in the inferior and septal regions [55]. Among patients with long QT syndrome, $61 \%$ were found to have regional ${ }^{123} \mathrm{I}-\mathrm{mIBG}$ defects, most commonly in the anteroseptal region. No difference in ${ }^{123} \mathrm{I}-m \mathrm{IBG}$ uptake pattern was noted between different long QT syndrome subtypes, between those with corrected QT (QTc) $>500 \mathrm{~ms}$ vs. those with QTc $<500 \mathrm{~ms}$, or between those suffering from cardiac arrest or syncope [56]. Other groups for which ${ }^{123} \mathrm{I}-m \mathrm{IBG}$ imaging abnormalities may predict the risk for ventricular tachyarrhythmias are those with idiopathic ventricular fibrillation [43, 44], arrhythmogenic right ventricular dysplasia [46],hypertrophic cardiomyopathy [47], Chagas cardiomyopathy [49], and after surgical correction of tetralogy of Fallot [57].

\section{Integration of 3-Dimensional Scar Models from ${ }^{123} \mathrm{I}-m$ IBGNeuro-Cardiac Imaging to Guide Ventricular Tachycardia Ablation}

The localized information of abnormal ${ }^{123} \mathrm{I}-m \mathrm{IBG}$ uptake pattern in the heart has raised the possibility that regional inhomogeneities of innervation may be related to ventricular arrhythmias and could provide guidance for VT ablations. Magnetic resonance imaging (MR), positron emission tomography (PET) and computed tomography (CT) have all been well validated to provide detailed information about the cardiac anatomy or the myocardial scar, which is usually the target for substrate-guided ventricular tachycardia ablations [58•, 59, 60, 61]. The current "gold standard" of defining myocardial scar is based on endocardial bipolar voltage recordings. Using a 3D mapping system a roving mapping catheter is moved sequentially along the endocardial surface of the left ventricle. Assuming that the voltage amplitude will be lower on scarred myocardium due to a paucity of live cells, a tiered classification with $>1.5 \mathrm{mV}$ for normal myocardium, $0.5-1.5 \mathrm{mV}$ for abnormal myocardium and $<0.5 \mathrm{mV}$ for scar is generally accepted for defining scar and its border zone in the left ventricle [62]. These clinical criteria were derived from several animal and patient studies correlating bipolar endocardial voltage recordings to areas of previous myocardial infarction.

Only recently has PET imaging been used to guide and facilitate VT ablation [58•]. Investigators at the University of Maryland showed a good correlation between PETderived metabolic scar maps and endocardial voltage maps in patients undergoing VT ablation $(\mathrm{r}=0.89, \mathrm{p}<0.05)$. Additionally, 3D scar reconstructions were successfully registered in patients with a commercial mapping system with an acceptable registration error of $3.7 \pm 0.7 \mathrm{~mm}$. Scar size, location, and border zone accurately predicted high- 
Table 2 Relevant studies on $m$ IBG scintigraphy and ventricular tachyarrhythmias

\begin{tabular}{|c|c|c|c|c|c|c|}
\hline Year & Author & $\mathrm{n}=$ & Patient Population & $\begin{array}{l}\text { Mean } \\
\text { baseline } \\
\text { LVEF }(\%)\end{array}$ & $\begin{array}{l}\text { Mean } \\
\text { Follow-up } \\
\text { (months) }\end{array}$ & Result \\
\hline 1991 & McGhie, et al. [39] & 27 & Post-MI & - & - & $\begin{array}{l}\text { Higher total defect score on }{ }^{123} \text { I- } m \text { IBG correlated } \\
\text { with the presence of VT and ventricular ectopy } \\
\text { within } 10 \text { days post-MI }\end{array}$ \\
\hline 2001 & Daliento, et al. [57] & 22 & $\begin{array}{c}\text { Post-surgical correction } \\
\text { of tetralogy of Fallot }\end{array}$ & - & - & $\begin{array}{l}\text { Those with VTA on } 24 \text {-hour Holter monitoring } \\
\text { had significantly reduced }{ }^{123} \text { I- } m \text { IBG uptake and } \\
\text { increased WR than those without. }\end{array}$ \\
\hline 2003 & Arora, et al. [42] & 17 & Prior ICD discharges & 39 & - & $\begin{array}{l}10 \text { patients with a history of ICD discharges had } \\
\text { significantly lower H/M and higher WR, as well } \\
\text { as reduced values for several HRV parameters, } \\
\text { than } 7 \text { patients without prior ICD discharges }\end{array}$ \\
\hline 2003 & Terai, et al. [47] & 44 & $\mathrm{HCM}$ & 59 & - & $\begin{array}{l}\text { Mean WR was significantly higher in } 15 \text { patients } \\
\text { with VTA on } 24 \text {-hour Holter monitor than in } \\
29 \text { without. }\end{array}$ \\
\hline 2006 & Paul et al. [43] & 20 & $\begin{array}{l}\text { Idiopathic VTA with } \\
\text { structurally normal } \\
\text { hearts }\end{array}$ & 72 & 86 & $\begin{array}{l}18 \text { recurrent episodes occurred in } 4 \text { patients with } \\
\text { abnormal }{ }^{123} \mathrm{I}-m \mathrm{IBG} \text { uptake, whereas only } 2 \\
\text { episodes occurred in } 1 \text { patient with normal } \\
{ }^{123} \mathrm{I} \text { - } m \text { IBG uptake. }\end{array}$ \\
\hline 2007 & Kioka, et al. [52] & 97 & $\begin{array}{l}\text { CHF }(53 \% \text { ICM, mean } \\
\text { NYHA class } 2.1)\end{array}$ & 29 & 65 & $\begin{array}{l}\text { Early and late } \mathrm{H} / \mathrm{M} \text { and } \mathrm{WR} \text { were all predictive } \\
\text { of SCD }\end{array}$ \\
\hline 2008 & Bax, et al. [50] & 50 & CHF (62 \% ICM) & 32 & - & $\begin{array}{l}\text { Patients underwent }{ }^{123} \mathrm{I}-m \mathrm{IBG} \text { prior to EP testing. } \\
\text { 4-hour }{ }^{123} \mathrm{I}-m \mathrm{IBG} \text { TDS } \geq 37 \text { predicted EP positivity. }\end{array}$ \\
\hline 2009 & Akutsu, et al. [44] & 86 & Prior VTA & 59 & 132 & $\begin{array}{c}\mathrm{H} / \mathrm{M} \leq 2.8 \text { predicted recurrence of VTA (HR } 3.6 \\
[95 \% \text { confidence interval, } 1.4-9.2, \mathrm{P}=0.007])\end{array}$ \\
\hline 2009 & Koutelou, et al. [53] & 25 & $\begin{array}{l}\text { Compensated CHF (NYHA } \\
\text { class I-II) and recent } \\
\text { ICD implantation. }\end{array}$ & 36 & 32 & $\begin{array}{l}\text { WR, in addition to HRV and baroreflex sensitivity, } \\
\text { predicted ICD discharges }\end{array}$ \\
\hline 2010 & $\begin{array}{l}\text { Boogers, et al. } \\
{[54 \bullet \bullet]}\end{array}$ & 116 & HF & 28 & 23 & $\begin{array}{l}{ }^{123} \text { I- } m \text { IBG SPECT was performed before ICD } \\
\text { implantation. Those with late }{ }^{123} \text { I- } m \text { IBG SPECT } \\
\text { defect score }>26 \text { had a greater risk of appropriate } \\
\text { ICD therapy }(52 \% \text { vs. } 5 \%, p<0.01) \text {. }\end{array}$ \\
\hline 2010 & Nishisato, et al. [45] & 60 & $\begin{array}{l}\text { Diverse group of patients } \\
\text { undergoing ICD } \\
\text { implantation }\end{array}$ & 49 & 29 & $\begin{array}{l}\text { At the time of ICD implant, }{ }^{123} \mathrm{I}-m \mathrm{IBG} \text { planar and } \\
\text { technetium SPECT perfusion imaging were } \\
\text { performed. H/M } \leq 1.9 \text { with summed perfusion } \\
\text { score } \geq 12 \text { independently predicted elevated risk } \\
\text { of ICD discharge. }\end{array}$ \\
\hline 2011 & Paul, et al. [46] & 42 & $\begin{array}{l}\text { Arrhythmogenic right } \\
\text { ventricular } \\
\text { cardiomyopathy }\end{array}$ & - & 143 & $\begin{array}{l}\text { Patients underwent }{ }^{123} \mathrm{I}-m \mathrm{IBG} \text { SPECT, and } 59 \% \\
\text { were found to have abnormal uptake. Abnormal } \\
\text { uptake predicted future VTA. }\end{array}$ \\
\hline 2011 & Miranda, et al. [49] & 26 & $\begin{array}{l}\text { Chagas cardiomyopathy } \\
\text { with and without VTA }\end{array}$ & 53 & - & $\begin{array}{l}\text { Compared to patients without of VTA on 24-hour } \\
\text { Holter monitoring, those with VTA had an } \\
\text { increased }{ }^{123} \text { I- } m \text { IBG defect score. }\end{array}$ \\
\hline 2012 & Kasama, et al. [51] & 56 & Dilated cardiomyopathy & 31 & 54 & $\begin{array}{l}\text { Late potentials and }{ }^{123} \mathrm{I}-m \mathrm{IBG} \text { imaging was } \\
\text { performed. Those with late potential positivity } \\
\text { and } \mathrm{WR}>50 \% \text { had an elevated risk of SCD. }\end{array}$ \\
\hline 2012 & Marshall et al. [48] & 27 & $\begin{array}{l}\text { HF patients receiving an } \\
\text { ICD for primary } \\
\text { prevention }\end{array}$ & 24 & 16 & $\begin{array}{l}\text { Low H/M and high total }{ }^{123} \mathrm{I}-m \mathrm{IBG} \text { SPECT defect } \\
\text { score at the time of ICD implantation predicts } \\
\text { future ICD discharges }\end{array}$ \\
\hline
\end{tabular}

resolution voltage map findings $(\mathrm{r}=0.87 ; \mathrm{p}<0.05)$. After integration of metabolic maps relevant information was available during the procedure. Low voltage recordings within wall segment displaying preserved metabolic activity were shown to be due to suboptimal catheter contact rather than actual myocardial wall disease. Integrated scar maps revealed metabolically active channels within the myocardial scar, which were not detected by voltage mapping. Moreover, $\mathrm{PET} / \mathrm{CT}$ maps correctly predicted non-transmural epicardial scar that was confirmed with epicardial mapping despite 
normal endocardial map. Similar results were obtained when using SPECT rather than PET radiopharmaceuticals [59].

An alternate attractive approach is the combination of PET with either CT or MR. While PET provides the metabolic differentiation between normal, hibernating, and scarred myocardium detailed anatomic information can be obtained from CT or MR with a spatial resolution of $\leq 1 \mathrm{~mm}$ or $2-3 \mathrm{~mm}$, respectively. Fusing both datasets can enable a synergistic metabolic and morphological evaluation, which extends beyond what each imaging technique can offer as a stand-alone technology. New elastic algorithms are able to register PET with CT or MR images from separate scanners fast and with an accuracy that is similar to manual elastic registration performed by human experts using up to 32 anatomic landmarks [63].

Current ongoing studies evaluate the utility of regional ${ }^{123} \mathrm{I}-m \mathrm{IBG}$ abnormalities to guide ablation in patients with preexisting cardiomyopathy and ventricular arrhythmias. 3D reconstructions of the regional left ventricular ${ }^{123} \mathrm{I}-m \mathrm{IBG}$ innervation have been compared to high density voltage maps. Using the conventional 17-segment analysis [64], the concordance between voltage-defined scar and ${ }^{123} \mathrm{I}-$ $m$ IBG denervation defect was found to be $75 \%$. Among the $25 \%$ discordant segments, $20 \%$ of the mismatch segments exhibited a larger ${ }^{123} \mathrm{I}-m \mathrm{IBG}$ defect size when compared to the voltage scar. While $90 \%$ of subsequent successful VT ablation sites were found in the area of voltage-defined scar, $10 \%$ were located in an area of abnormal ${ }^{123}$ I- $m$ IBG uptake that exhibited preserved voltage [65]. In a subset of patients who underwent repeat ${ }^{123} \mathrm{I}$ $m$ IBG imaging within 6 months of VT ablation, there was a trend toward increased late $\mathrm{H} / \mathrm{M}$ among patients with recurrent VT and decreased late $\mathrm{H} / \mathrm{M}$ in those without recurrent VT. While this difference did not reach statistical significance, it was hypothesized that regeneration of sympathetic nerves within areas of scar may predispose these patients to VT, and may be reflected by increased ${ }^{123} \mathrm{I}-m \mathrm{IBG}$ (Fig. 1) [66].

\section{Assessment of Cardiac Innervation with PET Radiotracers}

Position emitting radiotracers have also been used to image the cardiac sympathetic nervous system using PET $[67,68]$. The most common PET radiotracer studied for this purpose has been carbon-11 labeled hydroxyephedrine $\left({ }^{11} \mathrm{C}-\mathrm{HED}\right)$. ${ }^{11} \mathrm{C}$-HED is taken up by cardiac presynaptic neurons but not metabolized by synaptic degradation enzymes. Similar to the ${ }^{123} \mathrm{I}-m$ IBG planar and SPECT data, decreased ${ }^{11} \mathrm{C}$-HED PET retention in patients with HF has been associated with increased cardiac mortality and need for cardiac transplantation $[69,70]$. PET imaging of the cardiac nervous system

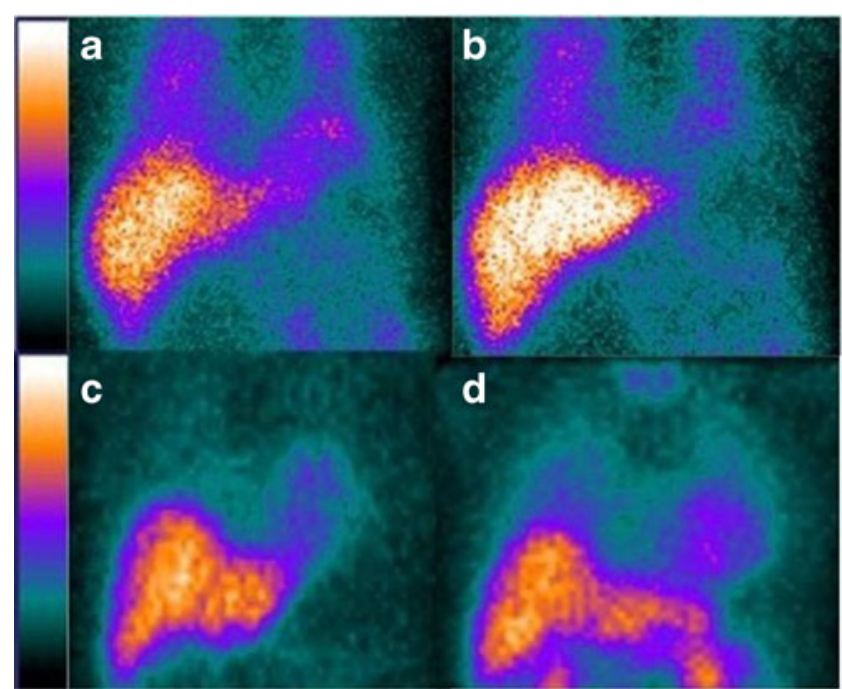

Fig. 1 Four-hour delayed MIBG images in panels A and B show decreased uptake of MIBG after ablation in a patient with VT. Panels $\mathrm{C}$ and $\mathrm{D}$ show increased uptake of MIBG after ablation in a different patient with VT. (A and C: before ablation, B and D: after ablation)

is advantageous over single photon imaging due to its superior spacial and temporal resolution compared to planar and SPECT techniques. However, widespread clinical use of ${ }^{11} \mathrm{C}$-HED is limited due to its relatively short 20 minute halflife and complex production requiring an onsite cyclotron, which makes the entire production costly [68].

Reduced cardiac neural regeneration after myocardial infarction has been theorized to be associated with arrhythmia risk. This was tested in a swine model, in which perfusion was assessed by ${ }^{13} \mathrm{~N}$-ammonia and innervation by ${ }^{11} \mathrm{C}$ epinephrine 4 to 12 weeks after myocardial infarction induced by balloon occlusion of the left anterior descending artery. Inducible VT was present in seven of the 11 animals studied, and in those with inducible VT, a significantly larger area of perfusion/innervation mismatch was present [71]. These findings lead to the PARAPET study, a prospective, observational trial, which will assess if hibernating myocardium or inhomogeneity of sympathetic innervation measured with PET can predict sudden cardiac death or cardiovascular mortality [72].

\section{Conclusions}

The clinical and prognostic value of imaging the cardiac nervous system in HF with ${ }^{123} \mathrm{I}-m \mathrm{IBG}$ is well established. While the radiotracer has not yet received FDA approval for cardiac application in the US, its potential role may also expand to the arena of electrophysiology, identifying and/or predicting sustained ventricular tachyarrhythmias in patients with cardiomyopathy, determining those who may benefit from ICD implantation, and pinpointing the site of 
ventricular arrhythmias to guide ventricular tachycardia ablation procedures.

Conflict of Interest Thomas Klein declares that he has no conflict of interest.

Vasken Dilsizian has received an investigator-initiated research grant from GE Healthcare; and is on the Advisory Board for GE Healthcare.

Qi Cao declares that he has no conflict of interest.

Wengen Chen declares that he has no conflict of interest.

Timm-Michael Dickfeld has received a research grant from GE.

Open Access This article is distributed under the terms of the Creative Commons Attribution License which permits any use, distribution, and reproduction in any medium, provided the original author(s) and the source are credited.

\section{References}

Papers of particular interest, published recently, have been highlighted as:

-. Of major importance

1. Zheng ZJ, Croft JB, Giles WH, Mensah GA. Sudden cardiac death in the United States, 1989 to 1998. Circulation. 2001;104:2158-63.

2. Chugh SS, Jui J, Gunson K, et al. Current burden of sudden cardiac death: multiple source surveillance versus retrospective death certificate-based review in a large U.S. community. J Am Coll Cardiol. 2004;44:1268-75.

3. Moss AJ, Zareba W, Hall WJ, et al. Prophylactic implantation of a defibrillator in patients with myocardial infarction and reduced ejection fraction. N Engl J Med. 2002;346:877-83.

4. Bardy GH, Lee KL, Mark DB, Poole JE, Packer DL, Boineau R, et al. Sudden Cardiac Death in Heart Failure Trial (SCD-HeFT) Investigators. Amiodarone or an implantable cardioverter-defibrillator for congestive heart failure. N Engl J Med. 2005;352:225-37.

5. Myerburg RJ, Interian Jr A, Mitrani RM, Kessler KM, Castellanos A. Frequency of sudden cardiac death and profiles of risk. Am J Cardiol. 1997;80:10F-9F.

6. Myerburg RJ, Mitrani R, Interian $\mathrm{Jr} \mathrm{A}$, Castellanos A. Interpretation of outcomes of antiarrhythmic clinical trials: design features and population impact. Circulation. 1998;97:1514-21.

7. Moss AJ, Greenberg H, Case RB, Zareba W, Hall WJ, Brown MW, et al. Long-term clinical course of patients after termination of ventricular tachyarrhythmia by an implanted defibrillator. Circulation. 2004;110:3760-5.

8. Zipes DP, Camm AJ, Borggrefe M, Buxton AE, Chaitman B, Fromer M, et al. ACC/AHA/ESC 2006 Guidelines for Management of Patients With Ventricular Arrhythmias and the Prevention of Sudden Cardiac Death: a report of the American College of Cardiology/American Heart Association Task Force and the European Society of Cardiology Committee for Practice Guidelines (writing committee to develop Guidelines for Management of Patients With Ventricular Arrhythmias and the Prevention of Sudden Cardiac Death): developed in collaboration with the European Heart Rhythm Association and the Heart Rhythm Society. Circulation. 2006;114:e385-484.

9. Raffel DM, Wieland DM. Development of $\mathrm{mIBG}$ as a cardiac innervation imaging agent. JACC Cardiovasc Imaging. 2010;3:111-6.

10. Dae MW, De Marco T, Botvinick EH, et al. Scintigraphic assessment of MIBG uptake in globally denervated human and canine heartsimplications for clinical studies. J Nucl Med. 1992;33:1444-50.
11. Flotats A, Carrio I, Agostini D, et al. Proposal for standardization of 123I-metaiodobenzylguanidine (MIBG) cardiac sympathetic imaging by the EANM Cardiovascular Committee and the European Council of Nuclear Cardiology. Eur J Nucl Med Mol Imaging. 2010;37:1802-12.

12. Veltman CE, Boogers MJ, Meinardi JE, et al. Reproducibility of planar (123)I-meta-iodobenzylguanidine (MIBG) myocardial scintigraphy in patients with heart failure. Eur J Nucl Med Mol Imaging. 2012;39:1599-608.

13. Chen W, Cao Q, Dilsizian V. Variation of heart-to-mediastinal ratio in (123)I-mIBG cardiac sympathetic imaging: its affecting factors and potential corrections. Curr Cardiol Rep. 2011;13:132-7.

14. Tsuchimochi S, Tamaki N, Tadamura E, et al. Age and gender differences in normal myocardial adrenergic neuronal function evaluated by iodine-123-MIBG imaging. J Nucl Med. 1995;36:969-74.

15. Cohn JN, Levine TB, Olivari MT, et al. Plasma norepinephrine as a guide to prognosis in patients with chronic congestive heart failure. N Engl J Med. 1984;311:819-23.

16. Brophy JM, Joseph L, Rouleau JL. Beta-blockers in congestive heart failure. A Bayesian meta-analysis. Ann Intern Med. 2001;134:550-60.

17. Foody JM, Farrell MH, Krumholz HM. beta-Blocker therapy in heart failure: scientific review. JAMA. 2002;287:883-9.

18. Merlet P, Valette H, Dubois-Rande JL, et al. Prognostic value of cardiac metaiodobenzylguanidine imaging in patients with heart failure. J Nucl Med. 1992;33:471-7.

19. Nakata T, Wakabayashi T, Kyuma M, Takahashi T, Tsuchihashi K, Shimamoto K. Cardiac metaiodobenzylguanidine activity can predict the long-term efficacy of angiotensin-converting enzyme inhibitors and/or beta-adrenoceptor blockers in patients with heart failure. Eur J Nucl Med Mol Imaging. 2005;32:186-94.

20. Cohen-Solal A, Esanu Y, Logeart D, et al. Cardiac metaiodobenzylguanidine uptake in patients with moderate chronic heart failure: relationship with peak oxygen uptake and prognosis. J Am Coll Cardiol. 1999;33:759-66.

21. Yamada T, Shimonagata T, Fukunami M, et al. Comparison of the prognostic value of cardiac iodine-123 metaiodobenzylguanidine imaging and heart rate variability in patients with chronic heart failure: a prospective study. J Am Coll Cardiol. 2003;41:231-8.

22. Agostini D, Verberne HJ, Burchert W, et al. I-123-mIBG myocardial imaging for assessment of risk for a major cardiac event in heart failure patients: insights from a retrospective European multicenter study. Eur J Nucl Med Mol Imaging. 2008;35:535-46.

23. Imamura Y, Fukuyama T, Mochizuki T, Miyagawa M, Watanabe K, Ehime MIBG. Heart Failure Study Investigators. Prognostic value of iodine-123-metaiodobenzylguanidine imaging and cardiac natriuretic peptide levels in patients with left ventricular dysfunction resulting from cardiomyopathy. Jpn Circ J. 2001;65:155-60.

24. Merlet P, Benvenuti C, Moyse D, et al. Prognostic value of MIBG imaging in idiopathic dilated cardiomyopathy. J Nucl Med. 1999;40:917-23.

25. Ogita H, Shimonagata T, Fukunami M, et al. Prognostic significance of cardiac (123)I metaiodobenzylguanidine imaging for mortality and morbidity in patients with chronic heart failure: a prospective study. Heart. 2001;86:656-60.

26. Gerson MC, Craft LL, McGuire N, Suresh DP, Abraham WT, Wagoner LE. Carvedilol improves left ventricular function in heart failure patients with idiopathic dilated cardiomyopathy and a wide range of sympathetic nervous system function as measured by iodine 123 metaiodobenzylguanidine. J Nucl Cardiol. 2002;9:608-15.

27. Erol-Yilmaz A, Verberne HJ, Schrama TA, et al. Cardiac resynchronization induces favorable neurohumoral changes. Pacing Clin Electrophysiol. 2005;28:304-10.

28. Gould PA, Kong G, Kalff V, et al. Improvement in cardiac adrenergic function post biventricular pacing for heart failure. Europace. 2007;9:751-6. 
29. Drakos SG, Athanasoulis T, Malliaras KG, et al. Myocardial sympathetic innervation and long-term left ventricular mechanical unloading. JACC Cardiovasc Imaging. 2010;3:64-70.

30. Burri H, Sunthorn H, Somsen A, et al. Improvement in cardiac sympathetic nerve activity in responders to resynchronization therapy. Europace. 2008;10:374-8.

31. Nishioka SA, MartinelliFilho M, Brandao SC, et al. Cardiac sympathetic activity pre and post resynchronization therapy evaluated by $123 \mathrm{I}-\mathrm{MIBG}$ myocardial scintigraphy. J Nucl Cardiol. 2007;14:852-9.

32. Verberne HJ, Brewster LM, Somsen GA, van Eck-Smit BL. Prognostic value of myocardial 123I-metaiodobenzylguanidine (MIBG) parameters in patients with heart failure: a systematic review. Eur Heart J. 2008;29:1147-59.

33. Dilsizian V, Chandrashekhar Y, Narula J. Introduction of new tests: low are the mountains, high the expectations. JACC Cardiovasc Imaging. 2010;3:117-9.

34. •- Jacobson AF, Senior R, Cerqueira MD, et al. Myocardial iodine123 meta-iodobenzylguanidine imaging and cardiac events in heart failure. Results of the prospective ADMIRE-HF (AdreView Myocardial Imaging for Risk Evaluation in Heart Failure) study. J Am Coll Cardiol. 2010;55:2212-21. This multicenter, prospective study on 961 patients from 96 sites provided validation of the independent prognostic value of $H / M$ in assessing heart failure patients.

35. Nakata T, Miyamoto K, Doi A, Sasao H, Wakabayashi T, Kobayashi $\mathrm{H}$, et al. Cardiac death prediction and impaired cardiac sympathetic innervation assessed by MIBG in patients with failing and nonfailing hearts. J Nucl Cardiol. 1998;6:579-90.

36. Kasama S, Toyama T, Kumakura H, Takayama Y, Ichikawa S, Suzuki T, et al. Effect of spironolactone on cardiac sympathetic nerve activity and left ventricular remodeling in patients with dilated cardiomyopathy. J Am Coll Cardiol. 2003;41:574-81.

37. Cao JM, Fishbein MC, Han JB, et al. Relationship between regional cardiac hyperinnervation and ventricular arrhythmia. Circulation. 2000;101:1960-9.

38. Podrid PJ, Fuchs T, Candinas R. Role of the sympathetic nervous system in the genesis of ventricular arrhythmia. Circulation. 1990;82:103-13.

39. McGhie AI, Corbett JR, Akers MS, et al. Regional cardiac adrenergic function using I-123 meta-iodobenzylguanidine tomographic imaging after acute myocardial infarction. Am J Cardiol. 1991;67:236-42.

40. Stanton MS, Tuli MM, Radtke NL, et al. Regional sympathetic denervation after myocardial infarction in humans detected noninvasively using I-123-metaiodobenzylguanidine. J Am Coll Cardiol. 1989;14:1519-26.

41. Mitrani RD, Klein LS, Miles WM, et al. Regional cardiac sympathetic denervation in patients with ventricular tachycardia in the absence of coronary artery disease. J Am Coll Cardiol. 1993;22:1344-53.

42. Arora R, Ferrick KJ, Nakata T, et al. I-123 MIBG imaging and heart rate variability analysis to predict the need for an implantable cardioverter defibrillator. J Nucl Cardiol. 2003;10:121-31.

43. Paul M, Schafers M, Kies P, et al. Impact of sympathetic innervation on recurrent life-threatening arrhythmias in the follow-up of patients with idiopathic ventricular fibrillation. Eur J Nucl Med Mol Imaging. 2006;33:866-70.

44. Akutsu Y, Kaneko K, Kodama Y, et al. The significance of cardiac sympathetic nervous system abnormality in the long-term prognosis of patients with a history of ventricular tachyarrhythmia. J Nucl Med. 2009;50:61-7.

45. Nishisato K, Hashimoto A, Nakata T, et al. Impaired cardiac sympathetic innervation and myocardial perfusion are related to lethal arrhythmia: quantification of cardiac tracers in patients with ICDs. J Nucl Med. 2010;51:1241-9.
46. Paul M, Wichter T, Kies P, et al. Cardiac sympathetic dysfunction in genotyped patients with arrhythmogenic right ventricular cardiomyopathy and risk of recurrent ventricular tachyarrhythmias. J Nucl Med. 2011;52:1559-65.

47. Terai H, Shimizu M, Ino $H$, et al. Cardiac sympathetic nerve activity in patients with hypertrophic cardiomyopathy with malignant ventricular tachyarrhythmias. J Nucl Cardiol. 2003;10:30410.

48. Marshall A, Cheetham A, George RS, Mason M, Kelion AD. Cardiac iodine-123 metaiodobenzylguanidine imaging predicts ventricular arrhythmia in heart failure patients receiving an implantable cardioverter-defibrillator for primary prevention. Heart. 2012;98:1359-65.

49. Miranda CH, Figueiredo AB, Maciel BC, Marin-Neto JA, Simoes MV. Sustained ventricular tachycardia is associated with regional myocardial sympathetic denervation assessed with 123Imetaiodobenzylguanidine in chronic Chagas cardiomyopathy. J Nucl Med. 2011;52:504-10.

50. Bax JJ, Kraft O, Buxton AE, et al. 123 I-mIBG scintigraphy to predict inducibility of ventricular arrhythmias on cardiac electrophysiology testing: a prospective multicenter pilot study. Circ Cardiovasc Imaging. 2008;1:131-40.

51. Kasama S, Toyama T, Kaneko Y, et al. Relationship between late ventricular potentials and myocardial 123I-metaiodobenzylguanidine scintigraphy in patients with dilated cardiomyopathy with mild to moderate heart failure: results of a prospective study of sudden death events. Eur J Nucl Med Mol Imaging. 2012;39:1056-64.

52. Kioka H, Yamada T, Mine T, et al. Prediction of sudden death in patients with mild-to-moderate chronic heart failure by using cardiac iodine-123 metaiodobenzylguanidine imaging. Heart. 2007;93:1213-8.

53. Koutelou M, Katsikis A, Flevari P, et al. Predictive value of cardiac autonomic indexes and MIBG washout in ICD recipients with mild to moderate heart failure. Ann Nucl Med. 2009;23:677-84.

54. •• Boogers MJ, Borleffs CJ, Henneman MM, et al. Cardiac sympathetic denervation assessed with 123-iodine metaiodobenzylguanidine imaging predicts ventricular arrhythmias in implantable cardioverter-defibrillator patients. J Am Coll Cardiol. 2010;55:2769-77. This prospective trial enrolled 116 heart failure patients undergoing ICD implantation, and documented a markedly increased risk of ventricular arrhythmias requiring ICD therapy in those with a more severe preimplant $m I B G$ total defect score.

55. Wichter T, Matheja P, Eckardt L, et al. Cardiac autonomic dysfunction in Brugada syndrome. Circulation. 2002;105:702-6.

56. Kies P, Paul M, Gerss J, et al. Impaired cardiac sympathetic innervation in symptomatic patients with long QT syndrome. Eur J Nucl Med Mol Imaging. 2011;38:1899-907.

57. Daliento L, Folino AF, Menti L, Zanco P, Baratella MC, Dalla VS. Adrenergic nervous activity in patients after surgical correction of tetralogy of Fallot. J Am Coll Cardiol. 2001;38:2043-7.

58. • Dickfeld T, Lei P, Dilsizian V, et al. Integration of three-dimensional scar maps for ventricular tachycardia ablation with positron emission tomography-computed tomography. JACC Cardiovasc Imaging. 2008;1:73-82. This was the first published experience of integration of 3-dimensional mapping systems and demonstrated its clinical usefulness in ablation of ventricular tachycardia.

59. Tian J, Smith MF, Ahmad G, Dilsizian V, Jimenez A, Dickfeld T. Integration of 3-dimensional scar models from SPECT to guide ventricular tachycardia ablation. J Nucl Med. 2012;53:894-901.

60. Tian J, Jeudy J, Smith MF, et al. Three-dimensional contrastenhanced multidetector CT for anatomic, dynamic, and perfusion characterization of abnormal myocardium to guide ventricular tachycardia ablations. Circ Arrhythmelectrophysiol. 2010;3:496-504.

61. Tian J, Ahmad G, Mesubi O, Jeudy J, Dickfeld T. Threedimensional delayed-enhanced cardiac MRI reconstructions to 
guide ventricular tachycardia ablations and assess ablation lesions. Circ Arrhythmelectrophysiol. 2012;5:e31-5.

62. Marchlinski FE, Callans DJ, Gottlieb CD, Zado E. Linear ablation lesions for control of unmappable ventricular tachycardia in patients with ischemic and nonischemic cardiomyopathy. Circulation. 2000;101:1288-96.

63. Shekhar R, Walimbe V, Raja S, et al. Automated 3-dimensional elastic registration of whole-body PET and CT from separate or combined scanners. J Nucl Med. 2005;46:1488-96.

64. Cerqueira MD, Weissman NJ, Dilsizian V, et al. Standardized myocardial segmentation and nomenclature for tomographic imaging of the heart: a statement for healthcare professionals from the Cardiac Imaging Committee of the Council on Clinical Cardiology of the American Heart Association. Circulation. 2002;105:539-42.

65. Ahmad G, Mesubi O, Dickfeld T, et al. Assessment of Regional Cardiac Innervation Using I123-Meta-iodobenzylguanidine for Guiding Ventricular Tachycardia Ablation [abstract]. In: Scientific Sessions - Heart Rhythm Society 2012; May 9-12, 2012; Boston, MA.

66. Klein T, Mesubi O, Ahmad G, et al. Assessment of Global Cardiac Innervation Using I123-Meta-iodobenzylguanidine Before and After Ventricular Tachycardia Ablation [abstract]. In: Scientific
Sessions - American Heart Association 2012; November 4-6, 2012; Los Angeles, CA.

67. Langer O, Halldin C. PET and SPET tracers for mapping the cardiac nervous system. Eur J Nucl Med Mol Imaging. 2002;29:416-34.

68. Bengel FM, Higuchi T, Javadi MS, Lautamaki R. Cardiac positron emission tomography. J Am Coll Cardiol. 2009;54:1-15.

69. Vesalainen RK, Pietila M, Tahvanainen KU, et al. Cardiac positron emission tomography imaging with [11C]hydroxyephedrine, a specific tracer for sympathetic nerve endings, and its functional correlates in congestive heart failure. Am J Cardiol. 1999;84:568-74.

70. Pietila M, Malminiemi K, Ukkonen H, et al. Reduced myocardial carbon-11 hydroxyephedrine retention is associated with poor prognosis in chronic heart failure. Eur J Nucl Med. 2001;28:373-6.

71. Sasano T, Abraham MR, Chang KC, et al. Abnormal sympathetic innervation of viable myocardium and the substrate of ventricular tachycardia after myocardial infarction. J Am Coll Cardiol. 2008;51:2266-75.

72. Fallavollita JA, Luisi Jr AJ, Michalek SM, et al. Prediction of arrhythmic events with positron emission tomography: PAREPET study design and methods. Contemp Clin Trials. 2006;27:374-88. 